\title{
Roseola Infantum
}

National Cancer Institute

\section{Source}

National Cancer Institute. Roseola Infantum. NCI Thesaurus. Code C128420.

An infection that is due to human herpesvirus (HHV) types 6 or 7; it is characterized by 35 days of high fever followed by the acute onset of a rosy, pink, non-pruritic, macular rash that is predominantly on the neck and trunk. 